\title{
Evidências de validade da escala brasileira de atitudes sociais de estudantes perante a política
}

Francisco Antonio Coelho Junior*, Cristiane Faiad, Thaís Mundim Baesse de Souza, Camila Puntel de Castro, Mayara Leporace Haddad Alves, Débora de Paula Alves

Universidade de Brasília (unb), Brasil

Recibido, abril 19/2017

Concepto de evaluación, agosto 14/2017

Aceptado, noviembre 10/2017
Referencia: Coelho Junior, F.A., Faiad, C., Baesse de Souza, T.M., de Castro, C.P., Haddad Alves, M.L. \& Alves, D.P. (2018). Evidências de validade da escala brasileira de atitudes sociais de estudantes frente à política Acta colombiana de Psicología, 21(2), 156-166. doi: http://www.dx.doi.org/10.14718/ ACP.2018.21.2.8

Resumo

\begin{abstract}
Objetivou-se apresentar as evidências de validade e confiabilidade de uma escala brasileira para medir atitudes políticas de estudantes brasileiros de nível superior ante seus comportamentos políticos. O estudo teve uma amostra de abrangência nacional $(\mathrm{N}=445)$, com estudantes brasileiros oriundos de distintos estados. Os resultados indicaram uma estrutura empírica sustentável (teste de Kaiser-Meyer-Olkin - кMO $=0,81$ ), com indicadores psicométricos considerados adequados à mensuração das atitudes políticas. Três fatores empíricos foram identificados: grau de conhecimento sobre política (15 itens, cargas fatoriais entre 0,31 e 0,82 , alfa $=0,82$, eigenvalue $=5,07$ e variância explicada $=18,78 \%$ ), afetos relativos à política ( 7 itens, cargas fatoriais entre 0,41 e 0,58 , alfa $=0,72$, eigenvalue $=3,17$ e variância explicada $=11,73 \%$ ) e intenções de comportamento político ( 2 itens, cargas fatoriais entre 0,70 e 0,72 , alfa $=0,80$, eigenvalue $=1,8$ e variância explicada $=6,8 \%$ ). Conclui-se que os resultados fortalecem a estrutura fatorial original da escala e mostram sua utilidade para a identificação de atitudes sociais ante comportamentos políticos.

Palavras-chave: psicologia política, comportamento político, evidências de validade, atitudes políticas.
\end{abstract}

\section{Evidencias de validez de la escala brasileña de actitudes sociales de estudiantes ante la política}

\begin{abstract}
Resumen
El objetivo de la presente investigación fue presentar las pruebas de confiabilidad y validez de una escala brasileña para medir las actitudes políticas de los estudiantes universitarios brasileños ante su comportamiento político. El estudio contó con una muestra nacional $(\mathrm{N}=445)$ de estudiantes brasileños de diferentes Estados. Los resultados indicaron una estructura empírica sustentable $(\mathrm{KMO}=.81)$, con indicadores psicométricos que se consideran adecuados para la medición de las actitudes políticas. Específicamente, se identificaron tres factores empíricos: nivel de conocimiento sobre la política (15 ítems, cargas factoriales entre .31 y .82 , alfa $=.82$, eigenvalue $=5.07$ y varianza explicada $=18.78 \%$ ), sentimientos acerca de la política ( 7 ítems, factoriales de .41 y .58 , alfa $=.72$, eigenvalue $=3.17$ y varianza explicada $=11.73 \%$ ) e intenciones del comportamiento político ( 2 ítems, factoriales de .70 y .72 , alfa $=.80$, eigenvalue $=1.8$ y varianza explicada $=6.8 \%$ ). Se llegó a la conclusión de que los resultados apoyan la estructura factorial original de la escala y muestran su utilidad en la identificación de las actitudes sociales ante la conducta política.

Palabras clave: psicología política, comportamiento político, evidencias de validez, actitudes políticas.
\end{abstract}

* Faculdade de Economia, Administração, Contabilidade e Gestão de Políticas Públicas (Face). Departamento de Administração e Programa de Pós-graduação em Administração. cep 70910-900. Brasília-df, Brasil. fercoepsi@gmail.com, acoelho@unb.br. Telefone: (+55 61) 3107-0759. 


\title{
Evidence of the validity and accuracy of the Brazilian social attitude of students scale towards politics
}

\begin{abstract}
The objective of this study was to present the validity and reliability evidences of a Brazilian scale to measure the political attitudes of Brazilian higher education students regarding their political behavior. The study had a nationwide sample $(\mathrm{N}=$ 445), with Brazilian students from different states. The results indicated a sustainable empirical structure $(\mathrm{KMO}=0.81)$, with psychometric indicators considered adequate to the measurement of political attitudes. Three empirical factors were identified: degree of political knowledge ( 15 items, factorial loads between 0.31 and 0.82 , alpha $=0.82$, eigenvalue $=5.07$ and explained variance $=18.78 \%$ ), feelings about politics $(7$ items, factorial loads between 0.41 and 0.58 , alpha $=0.72$, eigenvalue $=3.17$ and explained variance $=11.73 \%$ ) and intentions of political behavior $(2$ items, factorial loads between 0,70 and 0.72 , alpha $=$ 0.80 , eigenvalue $=1.8$ and explained variance $=6.8 \%$ ). It is concluded that the results strengthen the original factorial structure of the scale and show its utility for the identification of social attitudes regarding political behaviors. Key words: political psychology, political behavior, evidence of validity, political attitudes.
\end{abstract}

\section{INTRODUÇÃO}

O fenômeno do comportamento político é altamente complexo e vem se tornando objeto de estudo cada vez mais comum no campo da psicologia social. A investigação dos fenômenos de mudança relacionados ao comportamento político tornou-se objeto de estudo empírico, especialmente quanto à tomada de decisão e à participação política. Muito se tem falado em quanto e como as atitudes sociais e políticas influenciam o comportamento político.

As ciências sociais e humanas, como a ciência política, a psicologia, a sociologia e a gestão de políticas públicas, há tempos vêm se debruçando sobre a questão da gênese das crenças pessoais e dos modelos mentais relacionados ao comportamento de indivíduos, isoladamente ou em interação em grupos sociais. Parte importante dessa literatura sinaliza que as atitudes podem ser importantes facilitadoras de certos tipos de comportamentos manifestados por indivíduos e grupos sociais (Aarts, Verplanken \& Van Knippenberg, 1998; Ajzen, 2002b). Crenças e valores constantemente mantêm relação com a formação de atitudes, de modo que compreender a incidência desse fenômeno é de suma importância à análise da dinâmica humana e social.

Ressalta-se que o conceito de atitudes é de complexa demarcação teórica e empírica, pois parte do princípio que os indivíduos formam opiniões sobre um dado objeto e passam a agir especificamente perante este em função das suas crenças e conhecimentos sobre ele (Carneiro, Torres \& Ekman, 2016). Por sua vez, diferentes circunstâncias ou contingências podem fazer com que uma determinada atitude seja manifestada.
As atitudes referem-se, dessa forma, a predisposições ou a estados mentais que influenciam o indivíduo a escolher a ação na qual se engajará (Gagné \& Medsker, 1996). Envolvem informações sobre o objeto, as crenças e os valores pessoais, embora estes sejam mais gerais, enquanto as atitudes são necessariamente mais específicas e orientadas para determinadas finalidades e objetos.

O conceito de atitudes parece ser adequado ao estudo de como as pessoas compreendem, avaliam e se posicionam perante o objeto política. Nesse sentido e considerando que um dos pilares de uma sociedade democrática é a sua participação política, torna-se de fundamental importância o desenvolvimento de medidas científicas que tenham validade de construto e sejam precisas ao diagnóstico das atitudes dos cidadãos perante a política. Isso porque as atitudes ante um determinado objeto (no caso, a política) tendem a servir como base para as reações desencadeadas no contato com ele.

Considerar atitude como sinônimo de predisposição implica entendê-la como uma construção teórica ou como uma abstração analítica, referendando, inclusive, a elementos que não são reais, que não podem ser observados (Camino, 1996; Díaz, 2004). As atitudes são, assim, fundamentais à construção do comportamento político, uma vez que permitem dar sentido a esse objeto e compartilhar crenças sobre ele.

As atitudes, ainda, tendem a servir de quadro de referência dentro do qual ocorrem comportamentos direcionados ao objeto atitudinal (Altman, 1981; Díaz, 2004; Farr, 2001; Myers, 1999). Por isso, a relevância no diagnóstico das atitudes sociais ante a política, especialmente quando se 
considera a lacuna na literatura científica disponível no Brasil, de alguma medida de natureza semelhante que já contemple evidências de validade. Conforme relatam Pereira, Torres e Barros (2004), a maioria dos instrumentos disponíveis na literatura trata do construto "atitudes democráticas". Para esses autores, tais instrumentos não apresentam indicadores de validade e fidedignidade, tais como a Escala de Princípios Fundamentais da Democracia (Prothro \& Grigg, 1960) e o Índice de Orientação Pró-Democracia (Miller, Hesli \& Reisinger, 1995; Reisinger, Miller, Hesli \& Maher, 1994). Nesse contexto, destaca-se a importância deste trabalho no sentido propositivo de testar uma medida e sua validade de construto.

Acredita-se, aqui, que, por meio da investigação empírica das atitudes perante a política, é possível ter uma ideia da conduta que os indivíduos adotam em seu dia a dia, inclusive no papel de cidadão. Parte-se da premissa teórica de que as atitudes são fundamentais à análise e compreensão do pensamento político, capazes de influenciar o comportamento político (Ekman \& Amnå, 2012; Gomes \& Maheirie, 2011).

Ao encontro do discutido, a atitude é um conceito implícito, difícil de ser operacionalizado em medida (Fazio \& Olson, 2003). Historicamente, prevaleceu o modelo tridimensional sobre as atitudes que as segmenta pelos seus componentes afetivo, cognitivo e comportamental (Oskamp \& Schultz, 2005; Nascimento, Torres \& Pimentel, 2011). Mais recentemente, esses componentes foram tratados como diferenciados entre si, mantendo, quando o caso, uma relação de interdependência. Nesse sentido, atitude refere-se a um construto formado a partir de estímulo decodificado em processos cognitivos, afetivos e comportamentais capazes de gerar respostas cognitivas, afetivas e comportamentais (Oskamp \& Schultz, 2005; Kraus, 1995; Rodrigues, Assmar \& Jablonski, 2012). Refere-se a uma tendência psicológica que é expressa pela avaliação de uma entidade particular com um grau de favorabilidade e desfavorabilidade (Eagly \& Chaiken, 1993).

Atitudes podem ser entendidas como "predisposições aprendidas para responder de um modo consistentemente favorável ou desfavorável com relação a um dado objeto" (Fishbein \& Ajzen, 1975, p. 6). Atitudes, assim, podem ser compreendidas como avaliações que são feitas sobre pessoas, objetos e ideias, em que reações positivas ou negativas tornam o ser humano um observador constante (Wallace, Paulson, Lord \& Bond, 2005). Segundo o modelo tridimensional, as atitudes são constituídas por componentes cognitivos, constituídos pelos pensamentos e opiniões sobre um dado objetivo (apreciação objetiva do objeto); por componentes afetivos, que são reações emocionais (valores) ao objeto que gera a atitude, e componentes conativos (intenção comportamental), ou seja, ações capazes de eliciar comportamentos observáveis.

Por sua vez, a experiência social desempenha papel importante em moldar as atitudes. A maneira pela qual as atitudes são formadas pelas experiências cognitivas, afetivas e conativas vem sendo objeto de estudo por parte de cientistas sociais, haja visto que nem todas as atitudes são formadas da mesma maneira (Fehr \& Fischbacher, 2004; Glasman \& Albarracín, 2006; Tamayo, Pimenta, Rolim, Rodovalho \& Castro, 1996).

As experiências prévias bem como o repertório de conhecimento sobre o objeto são capazes de gerar influência sobre o tipo de atitude consolidada. Historicamente, as atitudes vêm sendo associadas à previsão de comportamentos. Segundo Díaz (2004), a vertente estruturalista refere-se às reações das pessoas perante a política, busca as diferenças entre o que se espera e o consenso que existe diante de determinados aspectos políticos. Pereira, Lima e Camino (2001), ao investigarem relações empíricas entre valores e atitudes democráticas, identificaram que a adesão ao sistema de valores religiosos associava-se à atitude negativa ante a democracia, enquanto essa atitude se relacionou positivamente com os valores pós-materialistas. Ajzen e Fishbein (1980) fizeram referência à teoria do comportamento planejado, em que normas subjetivas e o controle pensado sobre o comportamento, bem como o comportamento em si, são dimensões fundamentais à gênese das atitudes.

Para investigar cientificamente uma atitude, é necessário, primeiramente, verificar quais as crenças e convicções de uma pessoa a respeito de determinado assunto. Além disso, saber o que compreende e o que não consegue compreender, e saber quão ampla ou restrita/limitada é a sua perspectiva.

Ainda, a descrição de atitudes deve considerar o conhecimento da maneira pela qual um indivíduo pensa a respeito de uma questão, o que sente sobre esta ou em que estão fundamentadas suas convicções. O conteúdo psicológico e sociológico das atitudes, assim, representa, historicamente, $\mathrm{o}$ interesse dos pesquisadores sociais ao tentarem compreender as bases de sua gênese e consolidação, e quais os efeitos destas sobre o comportamento humano, de forma isolada ou em interação social.

Analisando-se a literatura sobre comportamento político, verifica-se que há diversas variáveis comumente associadas ao estudo da política no cenário nacional e internacional. Assim, a ideia de política encontra-se enraizada no atendimento das demandas, necessidades e interesses coletivos dos cidadãos e de outros segmentos sociais (como organizações, por exemplo), com vistas a atender à vontade geral em detrimento das vontades particulares. 
Parcela importante do movimento político incorpora elementos de cunho moral relativos às esferas de valores e do dever ser (Carneiro et al., 2016). Política, segundo Rousseau (1978), refere-se à forma de atividade ou de práxis humana, estreitamente relacionada ao poder, com o objetivo de promover a igualdade para a existência da liberdade. Política refere-se a um conjunto de meios que permitem alcançar os efeitos desejados, garantindo a ordem (social). Aação política está presente em diversos momentos da vida, tanto no aspecto privado quanto no público.

Política refere-se à ação de governar e ao o uso do poder para defender direitos de cidadania (Bobbio, Matteucci \& Pasquino, 1986). O convívio em sociedade torna necessário o desenvolvimento e integração de ações voltadas ao planejamento que promovam a cidadania. Política significa ter uma forma coerente e precisa de organizar a sociedade, não implica, necessariamente, a busca pelo controle do poder (Bobbio, 2000).

A política trata de todas as decisões que pautam nossa vida, e não apenas daquelas que se tomam no âmbito restrito do que, tradicionalmente, se entende como político. Segundo Prothro e Grigg (1960), utiliza-se o termo política no sentido mais amplo, ou seja, significando não apenas a esfera tomada convencionalmente como pública das relações humanas, mas também as diversas esferas em que ocorrem relações de poder e de deliberação coletiva.

A literatura aponta que uma finalidade fundamental da política consiste em manter a ordem pública, defender o território nacional e o bem social da população. Para tanto, torna-se fundamental ter gestores bem preparados para o exercício de representatividade dos interesses da população, de modo a oportunizar condições necessárias de sobrevivência e de interação.

Algumas premissas básicas são necessárias à formação de crenças e percepções favoráveis à ação política: concordância geral com a ideia de coletividade e de representatividade de interesses coletivamente compartilhados; aceitação e discussão das decisões a serem tomadas bem como dos projetos a serem estabelecidos; diálogo constante entre todas as camadas da população, que devem se sentir representadas.

Já a ciência política, segundo Bobbio (2000), consiste, fundamentalmente, no estudo dos fenômenos e estruturas politicas, que deve ser conduzido com sistematicidade (rigorosidade metodológica) e contar com exame meticuloso dos fatos. Outro princípio defendido pelo autor refere-se a que a ciência politica deve ser analisada por meio de argumentos racionais, especialmente pela aplicação à análise do fenômeno político no escopo metodológico das ciências empíricas.
Nesse contexto, a compreensão de variáveis de ordem individual e social torna-se de fundamental importância à análise da postura e comportamento dos indivíduos e grupos acerca da política (Ajzen, 2002a). Uma das variáveis referese às atitudes dos indivíduos quanto à política. Sobre isso, consideram-se algumas questões: uma atitude mais favorável à política tende a ter relação com o engajamento do indivíduo em movimentos sociais ou de luta pela realização efetiva de seus direitos? Por outro lado, uma atitude desfavorável tem relação com o fato de um indivíduo, por exemplo, anular seu voto nas eleições? Estas e outras questões podem ser elaboradas considerando a premissa fundamental de que crenças e percepções de natureza individual e referentes ao contexto podem determinar o tipo de comportamento ou ação manifestada pelos indivíduos em torno de sua maior ou menor participação ou engajamento político.

Isso posto, o presente trabalho objetiva apresentar as etapas de construção e validação psicométrica exploratória da escala brasileira para identificar e medir, empiricamente, as atitudes sociais perante a política. Visa apresentar as evidências de validade de construto e precisão da escala relatando os índices de confiabilidade da medida. Espera-se, com isso, que seja sanada uma lacuna na literatura sobre o tema, até então carente de medidas psicométricas válidas e fidedignas segundo os preceitos preconizados na teoria sobre evidências de validade.

\section{MÉTODO}

\section{Desenho}

Esta pesquisa tem caráter exploratório. Como se trata da apresentação de todos os procedimentos de construção e validação psicométrica da escala brasileira de atitudes sociais e políticas, optou-se pelo tipo de delineamento descritivo, com recorte temporal transversal de coleta de dados junto a uma amostragem, por acessibilidade e conveniência, de estudantes brasileiros, como será relatado adiante.

A escala aqui relatada foi construída com base nos relatos de pesquisas empíricas sobre a temática relativa a "atitudes sociais e políticas", bem como de acordo com a literatura psicológica sobre comportamento político. Conforme visto, variáveis de atitudes vêm, tradicionalmente, se correlacionando positivamente com comportamento.

Numa sociedade democrática, como a brasileira, o comportamento político é de fundamental importância à análise científica de como os cidadãos se adaptam às normas e papéis sociais, e como elaboram representações sociais acerca da própria participação dos rumos políti$\cos$ da nação. Em face disso, torna-se de fundamental a 
construção e testagem, em termos de suas evidências de validade, de medidas que tenham validade de construto e sejam precisas à identificação de atitudes mais ou menos favoráveis quanto à política.

\section{Participantes}

A pesquisa foi realizada com 445 estudantes provenientes de uma universidade pública brasileira. Os participantes eram provenientes dos cursos de Administração, Gestão de Políticas Públicas, Sociologia, Direito e outros. A amostra caracterizou-se por acessibilidade e conveniência, o que resultou em um perfil bastante homogêneo em sua composição. Ressalta-se que a amostragem atendeu aos critérios estatísticos de generalização e validação psicométrica apresentados por Tabachnick e Fidell (2001).

Notou-se que a amostra esteve bastante homogênea quanto à participação de homens $(50,8 \%)$ e mulheres (49,2\%), com o predomínio de pessoas que cursavam a metade da graduação para o final do seu curso (78,8 \%). Verificou-se, ainda, que 48,3\% afirmaram conversar esporadicamente sobre política, e apenas 11,5\% afirmaram dialogar diariamente. Identificou-se, também, que 83,3 \% afirmaram não estarem atualmente engajados em nenhum movimento político.

Para 76,1\% dos participantes, a principal fonte de acesso a notícias sobre políticas é por meio de sites diversos. Para $77,9 \%$ dos respondentes, a política é de grande importância à sua vida.

\section{Construção da medida, validação semântica e validação por juizes}

A construção do instrumento ocorreu em uma série de oficinas de trabalho, nas quais eram apresentados o referencial teórico estudado, os objetivos, o problema de pesquisa, os conceitos e a metodologia que norteariam a atividade. O objetivo das oficinas consistiu em coletar críticas e sugestões aos itens do questionário, baseadas na discussão sobre o tema de estudo.

Após a análise pormenorizada do instrumento de atitudes ante a política e a avaliação crítica de nove juízes, entre experts e professores da universidade em estudo vinculados aos departamentos de Gestão de Políticas Públicas, Sociologia, Psicologia, Ciência Política e Administração, o referido instrumento foi reformulado e novamente revisado antes que fosse elaborada sua versão final. Ressalta-se que os itens foram elaborados e aprimorados considerando-se os 12 critérios e regras de qualidade na construção de itens estabelecidos por Pasquali (1999) e pela American Educational Research Association (2014), além de considerar algumas das reflexões elaboradas porAsch (1971), Friedman, Carlsmith e
Sears (1970), e Fishbein e Azjen (1975), na discussão sobre dilemas enfrentados no uso de medidas para levantamento e análise do conceito de atitudes nas ciências sociais.

\section{Instrumento}

A versão preliminar do questionário de atitudes sociais perante a política, para sua primeira aplicação exploratória como se propõe neste estudo, contou com três dimensões de análise: grau de conhecimento sobre o objeto (no caso, política), emoções ou afetos despertados por tal objeto e intenção comportamental relativa a ele.

O primeiro fator teórico hipotético, "Grau de conhecimento sobre política", identifica o que significa ou representa esse fenômeno ao indivíduo. Refere-se à percepção do indivíduo sobre suas definições, sua importância, utilidade e suas relações com o estabelecimento dos anseios compartilhados da comunidade (atendimento das necessidades coletivas). Os itens foram associados a uma escala de frequência, tipo Likert, ancorada em 11 pontos, na qual 0 (zero) correspondia a "Nunca" e 10 (dez) a "Sempre".

O segundo, "Emoções ou afetos sobre política", referese ao tipo de sentimento despertado pela política sobre os indivíduos. A literatura relata sensações relativas à pouca participação popular nas decisões democráticas aliadas à percepção de alienação ou descrédito quanto à importância da política. Sentimentos de ignorância e de raiva são, também, considerados no fator teórico hipotético. Com frequência, há confusão entre o que é política e o que são os partidos políticos.

Tanto afetos positivos ou agradáveis quanto negativos ou desagradáveis foram transformados em itens. Esses itens também foram associados a uma escala de frequência, do tipo Likert, de 11 pontos, idêntica à descrita anteriormente.

O terceiro e último agente de avaliação em hipótese e a ser testado empiricamente corresponde à "Intenção comportamental sobre política". Esse foco refere-se à percepção do respondente sobre o que ele faz ou faria em relação à sua participação política, ao seu maior ou menor engajamento político. Itens referentes a participações em ações que legitimem o pensamento político foram elaborados tratando-se de um autojulgamento, pois o indivíduo avaliou o quanto suas iniciativas e comportamentos são incentivados ou rechaçados pelas suas atitudes. Os itens também foram agrupados em escala de frequência do tipo Likert, ancorada em 11 pontos, na qual 0 (zero) correspondia a "Nunca" e 10 (dez) a "Sempre".

No que se refere à análise e validação semântica do questionário, uma análise minuciosa das instruções do instrumento foi realizada, inclusive com os juízes experts, a fim de evitar ambiguidades, tendenciosidades ou erros 
na análise das orientações gerais que pudessem atrapalhar o seu preenchimento. De acordo com Pasquali (1999), os itens do instrumento foram analisados quanto à sua precisão, fidedignidade, clareza, parcimônia e objetividade.

A validação final por juízes foi realizada junto a nove professores experts da Universidade de Brasília, diretamente envolvidos em atividades de pesquisa sobre o comportamento político ou que estudassem os processos sociais e cognitivos relativos à gênese e mudança de atitudes. A validação permitiu ajustar alguns itens pertinentes à parcimônia da linguagem utilizada, além de promover a modificação das orientações gerais da escala, o que facilitou a compreensão por parte do respondente. Foi, inclusive, elaborada uma carta de sensibilização, enviada juntamente com o instrumento, de modo a encorajar o provável respondente a participar da pesquisa e explicar sobre os objetivos dela.

Finalizados os procedimentos de validação semântica e por juízes, planejou-se o início da coleta de dados mais ampla, a qual foi realizada totalmente a distância.

\section{Procedimento}

$\mathrm{O}$ instrumento foi digitalizado em formato eletrônico e disponibilizado na ferramenta Google Docs. Como o objetivo central deste trabalho consistia na análise das evidências de validade da medida construída, optou-se pela coleta eletrônica de dados, o que permitiu maior amplitude e generalização amostral.

Inicialmente, tanto a divulgação da pesquisa quanto o link para a participação nesta foram disponibilizados pelos pesquisadores em redes sociais informacionais. Concomitantemente, foi obtida uma listagem de e-mails de alunos de cursos de graduação em Administração Pública cadastrados no ambiente virtual de aprendizagem (AVA), da universidade em questão.

Para obter maior alcance de respostas ao questionário, optou-se, também, por expandir a coleta de dados para graduandos dos departamentos de Sociologia, Ciência Política, Gestão de Políticas Públicas, Direito e Administração. Optou-se por essa decisão metodológica por se tratarem de departamentos cujas temáticas de debate abordavam a gênese e formação do comportamento político nos cidadãos. Esses departamentos inserem tal temática na grade curricular, por meio de palestras, atividades de extensão à comunidade acadêmica e outras ações.

Foi enviado aos prováveis respondentes da pesquisa um e-mail individual, que continha um link para o instrumento de atitudes e uma carta de sensibilização, cujo conteúdo visava motivar sua participação. Os e-mails dos estudantes foram obtidos junto às secretarias dos departamentos.
Tal carta de sensibilização descrevia os objetivos da pesquisa e ressaltava, ainda, a importância da participação espontânea e a relevância e necessidade das respostas serem condizentes com a sincera opinião do respondente. Outro aspecto essencial da carta de sensibilização referia-se à garantia de sigilo das opiniões expressas pelos respondentes.

Todos os procedimentos a serem seguidos para o correto preenchimento da escala foram previamente definidos, a fim de minimizar possíveis vieses de análise do respondente e, assim, evitar erros no preenchimento do instrumento. Testes foram feitos pela equipe de pesquisa junto ao instrumento e ao cadastro das respostas no banco de dados, para não haver erros. O conteúdo do e-mail e do instrumento, autoexplicativo e autoaplicável, foi criteriosamente analisado, a fim de torná-lo objetivo e compreensível para a análise e posterior julgamento dos respondentes.

\section{Análise de dados}

As respostas de todos os participantes ao instrumento de pesquisa foram registradas em um arquivo de dados eletrônico. Em seguida, foram importadas para o software Statistical Package for the Social Sciences (SPSS), versão 22.0, para a análise dos dados da pesquisa.

Inicialmente, os dados foram submetidos a análises estatísticas exploratórias e descritivas. Identificou-se a ocorrência de casos extremos (outliers) uni e multivariados, e foi avaliada a influência deles no padrão das respostas obtidas. De 461 casos obtidos, houve a redução para 445 (16 outliers), sendo esta a amostra final do estudo.

A fim de identificar casos extremos univariados, houve a transformação das variáveis em escore padronizado (z). Adotou-se o critério de exclusão das respostas iguais ou superiores a $3(\mathrm{p}<0,001$, bicaudal). Já especificamente nos casos extremos multivariados, procedeu-se à análise estatística com base na distância mahalanobís $(\mathrm{a}=0,001)$. Ressalta-se que todas as etapas de análise deste trabalho foram realizadas com e sem casos extremos uni e multivariados, a fim de se identificarem eventuais diferenças nos resultados que tais dados poderiam provocar. A amostra final contou com 445 casos.

A evidência de validade da escala foi analisada por meio da Análise Fatorial Exploratória. Como se trata de uma primeira busca por validação interna da medida construída, optou-se por não realizar a análise fatorial confirmatória neste momento, para fins de realização deste estudo.

Iniciou-se a análise da sua estrutura empírica com a análise dos componentes principais, bem como a análise da multicolinearidade e fatorabilidade da matriz (por meio da análise do tamanho da amostra, tamanho das intercorrelações acima de 0,32 , distribuição dos valores próprios, scree plot, 
teste de esfericidade de Bartlett AIC, $\operatorname{com} p<0,001$, e análise do KMO) e análise paralela. Posteriormente, realizaram-se análises de fatoração dos eixos principais (PAF, por sua sigla em inglês).

Utilizou-se, posteriormente, o método PAF, com rotação oblíqua (direct oblimin), a fim de verificar as correlações entre os fatores. Procedeu-se, também, ao cálculo de escores fatoriais. Destaca-se que há tipos diferentes de critérios para a determinação do número de fatores, os quais podem ser reduzidos a três: critérios estatísticos (testes de significância), critérios convencionais e a relevância do componente ou fator (Pasquali, 1999).

Esses três critérios anteriores foram utilizados somados a outros critérios para determinação fatorial da matriz: valores próprios $>1$, mínimo de $3 \%$ da variância explicada, scree plot, determinação de cargas fatoriais $(>0,30)$, análise de correlação entre fatores, consistência interna (alfa de Cronbach) e interpretabilidade das soluções encontradas.

\section{Considerações éticas}

Cada participante assinou o Termo de Consentimento Livre e Esclarecido, que continha informações acerca da pesquisa, contato dos profissionais responsáveis e esclarecimentos acerca da não obrigatoriedade de participar da pesquisa e da possibilidade de interromper sua participação.

\section{RESULTADOS}

Nesta seção, apresentam-se os resultados decorrentes dos procedimentos de PAF que foram adotados. Apresentamse as evidências psicométricas da medida bem como seus parâmetros de fidedignidade e precisão.

Os resultados indicaram que, nas soluções fatoriais da escala extraída da matriz sem casos extremos, houve um aumento tanto da variância total explicada quanto do valor próprio (eigenvalue) dos componentes. Observou-se, também, ainda comparando os resultados obtidos com e sem os casos extremos identificados, que as posições dos itens na escala foram modificadas, aumentando-se o tamanho das cargas fatoriais.

Os índices de consistência interna dos fatores aumentaram em relação à análise com casos extremos, porém o KMO permaneceu quase inalterado em seu valor final, decidindose, então, pela análise e interpretação dos resultados obtidos com a eliminação dos casos extremos uni e multivariados identificados. Ressalta-se que esse procedimento de eliminação de casos extremos pôde ser realizado em virtude de a amostra ter sido considerada abrangente, o que permitiu a eliminação desses casos sem comprometer o número final de participantes. Ressalta-se que não houve perda significativa de dados a ponto de inviabilizar as análises estatísticas propostas.
A análise gráfica do scree plot, feita por intermédio dos componentes principais, indicou que a matriz de correlações se apresentou fatorável, com KMO $=0,81$ e indicação de até sete fatores. Verificou-se, também, que o primeiro fator se destacou dos demais em termos dos valores próprios e da porcentagem da variância explicada. A solução com sete fatores, obtida por meio da análise dos componentes principais, sugeriu uma estrutura fatorial pouco parcimoniosa. Alguns componentes nem mesmo eram teoricamente defensáveis (Pasquali, 1999).

Assim, procederam-se à PAF, forçando-se a solução com seis, cinco e quatro fatores. A estrutura empírica encontrada mostrou que todos os itens dos últimos fatores pertenciam, concomitantemente, aos demais fatores, compartilhando carga fatorial entre si. Houve forte correlação entre os fatores, o que indica outras soluções fatoriais para a escala, que objetivam o alcance de uma estrutura empírica mais coerente e parcimoniosa.

$\mathrm{Na}$ solução forçada em três fatores, também por meio da PAF, com rotação oblíqua e tratamento listwise dos dados omissos, encontrou-se uma estrutura empírica mais parcimoniosa. As cargas fatoriais variaram de 0,82 a 0,31 . Optou-se por não retirar os itens com cargas próximas à 0,30 , por serem consideradas minimamente aceitáveis, conforme Fabrigar, Wegener, MacCallum e Strahan (1999) e Hair, Black, Babin e Anderson (2010). O primeiro fator, denominado "Grau de conhecimento sobre política", constituído por 15 itens, corresponde à avaliação dos respondentes sobre o que é política. $\mathrm{O}$ alfa foi de 0,82 , com valor próprio de $5,07 \mathrm{e}$ variância explicada de 18,78 \%. Mais especificamente, esse fator empírico diz respeito ao grau de informações que os respondentes possuem sobre características da política. Ou seja, sua importância ao andamento de uma sociedade democrática, bem como as reações que os indivíduos têm ao mencionar o termo política. A importância da política à manutenção do conceito de sociedade bem como sua relação com o conceito de democracia também foram conteúdos contidos nos itens.

O segundo fator empírico, "Afetos sobre política", com sete itens, apresentou um alfa de 0,72 , com valor próprio de 3,17 . O fator refere-se àquilo que, na opinião dos respondentes, leva os indivíduos a envolverem-se com a política. Dimensões concernentes à paixão pela política, bem como àquilo que leva as pessoas a engajarem-se nesta são contempladas nesse fator. Na Tabela 1 , apresentam-se os dados de evidências de validade.

O terceiro fator, "Intenções comportamentais perante a política", ficou contemplado com dois itens, com alfa de 0,80 . Esse fator trata das percepções acerca da utilização da política para fins pessoais, indo de encontro aos preceitos esperados no pensamento político, que dão ênfase ao 
Tabela 1

Cargas fatoriais dos fatores "Grau de conhecimento sobre política, emoções e intenção conativa"

\begin{tabular}{|c|c|c|c|}
\hline \multirow[t]{2}{*}{ Descrição das variáveis } & \multicolumn{3}{|c|}{ Cargas fatoriais } \\
\hline & Fator 1 & Fator 2 & Fator 3 \\
\hline A política é importante para o desenvolvimento do Brasil como nação. & 0,82 & & \\
\hline Política é importante para o desenvolvimento de um país. & 0,72 & & \\
\hline $\begin{array}{l}\text { É importante a participação efetiva dos cidadãos em questões relacionadas a tomadas de decisão } \\
\text { política. }\end{array}$ & 0,60 & & \\
\hline Política se refere à arte de governar e utilizar o poder para defender os direitos de cidadania. & 0,56 & & \\
\hline A política deve servir à democracia. & 0,54 & & \\
\hline É por meio da política que as pessoas conseguem acessar seus direitos de cidadão. & 0,51 & & \\
\hline A função da política é defender interesses coletivos da sociedade. & 0,48 & & \\
\hline É por meio da política que se tem democracia. & 0,46 & & \\
\hline $\begin{array}{l}\text { A política no Brasil está em um cenário muito distante do atendimento real dos interesses da } \\
\text { sociedade civil. }\end{array}$ & 0,44 & & \\
\hline O acesso à informação é um fator que determina a participação das pessoas na política. & 0,44 & & \\
\hline $\begin{array}{l}\text { Política refere-se à capacidade que as sociedades têm de fazer com que as pessoas cooperem na } \\
\text { direção de um objetivo estabelecido entre elas. }\end{array}$ & 0,41 & & \\
\hline Entender que política vai além do Congresso Nacional faz com que as pessoas se engajem mais. & 0,37 & & \\
\hline A política faz parte da vida das pessoas. & 0,33 & & \\
\hline No Brasil, as pessoas confundem política com partido político. & 0,31 & & \\
\hline O sentimento mais comum perante a política é o de impotência. & 0,31 & & \\
\hline As pessoas se envolvem na política por acreditarem na sua importância. & & 0,58 & \\
\hline O cenário político brasileiro vive um momento de respeito e valorização da ética. & & 0,56 & \\
\hline A função da política é atender às necessidades de bem-estar da população. & & 0,55 & \\
\hline As pessoas se envolvem na política por paixão. & & 0,53 & \\
\hline As pessoas se dedicam à política por entenderem que ela é fundamental à vida humana. & & 0,50 & \\
\hline Engajamento é o sentimento mais comum perante a política. & & 0,47 & \\
\hline No Brasil, acredito que as pessoas sabem o quão importante é a política para suas vidas. & & 0,41 & \\
\hline Quem se dedica à política, o faz por motivos pessoais, para tirar vantagem. & & & 0,72 \\
\hline No Brasil, as pessoas se dedicam à política para satisfazer seus próprios interesses. & & & 0,70 \\
\hline Número de itens & 15 & 7 & 2 \\
\hline \% variância explicada & 18,78 & 11,73 & 6,8 \\
\hline Valor próprio (eigenvalue) & 5,07 & 3,17 & 1,8 \\
\hline Consistência interna & 0,82 & 0,72 & 0,80 \\
\hline
\end{tabular}

$\mathrm{N}=445$

Fonte: dados primários da pesquisa.

atendimento de interesses coletivos da sociedade. A Tabela 1 ilustra todas as informações encontradas.

Nota-se que os três fatores abarcaram atitudes favoráveis ou desfavoráveis perante a política. Os dois itens constantes no terceiro fator têm polaridades ou facetas de conteúdo negativo (Pasquali, 1999), mas que são complementares aos fatores anteriores. Atitude, variável humana, é medida em termos das reações positivas ou negativas quanto ao objeto, como encontrado no caso deste trabalho.

Novas sugestões são feitas a seguir. De qualquer forma, pelo critério estatístico e de relevância para a análise do tema, optou-se por manter esses itens nessa estrutura com três fatores. A escala, portanto, apresenta indícios de validade que permitem sua aplicação em um contexto maior e identifica quais são as atitudes sociais dos indivíduos perante a política.

\section{DISCUSSÃO}

O objetivo deste estudo foi construir e validar, empiricamente, de forma exploratória, uma escala brasileira de atitudes perante a política. Acredita-se que esse objetivo foi 
atingido. Todos os procedimentos de validação (semântica, por juízes e empírica) foram relatados, e os resultados podem ser considerados positivos quanto a evidências de validade.

Três fatores empíricos foram identificados. Um concernente ao grau de conhecimento sobre o que é política, outro referente ao tipo de emoções ou afetos despertados por esse objeto e um terceiro referente a intenções comportamentais, concernentes à literatura ora apresentada.

O construto "atitude" é de difícil mensuração, e sua independência (ou interdependência) de outros fenômenos, como emoções e comportamento observável, precisa ser mais bem investigada cientificamente. Os achados deste trabalho corroboram, em parte, os resultados encontrados em Camino (1996) e Pereira et al. (2001). Conceitos similares disponíveis na literatura, tais como atitudes democráticas (Pereira et al., 2004), apresentaram uma medida unifatorial. Isso reflete a dificuldade de se operacionalizar o construto atitude em termos do desenvolvimento de métricas associadas à sua aferição.

O coeficiente de fidedignidade obtido indica que a escala pode ser aperfeiçoada. Faz-se mister, para replicações posteriores, que sejam agregados itens mais profundamente relativos a propriedades psicológicas das atitudes com ênfase na intenção conativa ante o fenômeno.

Ao analisar os resultados, percebe-se que foi obtido um posicionamento democrático dos participantes sobre o objeto, não suas disposições psicológicas, base do conceito de atitude. Ressalta-se que não era de se esperar obter um coeficiente elevado, uma vez que trata de um constructo complexo e de difícil operacionalização, além do que este é um estudo exploratório. Novas evidências de validade devem ser testadas em outras amostras, a fim de buscar generalidade à medida aqui relatada.

Outro aspecto limitador refere-se à provável influência de ideologias ou posições pró ou contrárias ao objeto "política". Uma das hipóteses pode ter sido a influência pelo viés de desejabilidade social.

A escala de atitudes perante a política é uma medida precisa, confiável e válida, por permitir a investigação de parte das questões relacionadas à formação de atitudes sociais e sua provável influência sobre o comportamento político. Tal relação precisa ser testada empiricamente.

$\mathrm{O}$ instrumento apresentou, em sua versão final, itens com conteúdo favorável e desfavorável relativos às atitudes sociais. A adoção de itens com sentido desfavorável e favorável em uma mesma escala, embora aconselhado por teóricos da área (Pasquali, 1999), parece não ter alcançado o efeito final esperado, já que esses itens não contribuíram significativamente para o instrumento, obtiveram, inclusive, as menores cargas fatoriais e comunalidades. Sugere-se que tais itens sejam reformulados, já que estes carregam expressões fortes como interesses pessoais ou tirar vantagem, que podem direcionar a análise dos indivíduos.

Uma sugestão para estudos futuros refere-se à formulação de um instrumento de medida especificamente direcionado à identificação de fatores psicossociais potencialmente inibidores de atitudes favoráveis. Tal instrumento deverá agregar uma dimensão simbólica do termo política e visar a mensuração do grau de envolvimento do respondente com ações de natureza política em sua comunidade.

Ainda, itens devem ser acrescidos com vistas a mensurar o quanto cada respondente compartilha crenças favoráveis sobre política. Ametodologia qualitativa pode, inclusive, ser uma relevante ferramenta nesse sentido, visto que poderia ser utilizada para aprofundar a investigação das variáveis relacionadas a atitudes e comportamentos negativos quanto à política.

Espera-se que a extensão do conceito de atitudes diante de um objeto social, tal como a política, permita uma análise mais complexa e detalhada acerca do comportamento político. Contudo, esse conceito precisa ser utilizado em outros estudos, com perfis amostrais distintos, a fim de verificar a generalidade dos resultados, a consistência e estabilidade das estruturas empíricas encontradas.

Como limitações, verifica-se que a confusão conceitual no campo de atitudes vem sendo uma constante nos estudos da área, o que dificulta sua operacionalização empírica. Há distintas perspectivas conceituais nas pesquisas em psicologia social e psicologia política (como atitudes democráticas e atitudes pré-democráticas, dentre outras) que se propõem a investigar atitudes. Porém, tais conceitos não estão plenamente alinhados aos instrumentos e medidas a eles associados. Há casos em que tais instrumentos avaliam aquém ou além daquilo proposto no conceito.

Sugere-se, para estudos futuros, que haja a reaplicação do instrumento aqui validado em diferentes países, de modo a conferir abrangência e consistência à medida encontrada. Sugere-se, também, a investigação conceitual e empírica de possível relação entre variáveis como comportamento político, engajamento político, cognição política, cognição social e afetos despertados pelo comportamento político.

Mostra-se necessário aprimorar a medida de atitude descrita neste trabalho. A confusão entre política e partidos políticos pode, também, ser explorada por meio de novos itens. Outros procedimentos de análise de dados, como modelagem por equações estrutural (análise fatorial confirmatória) e discriminante, comparando-se a outros conceitos e medidas, devem ser testados. 


\section{REFERÊNCIAS}

Aarts, H., Verplanken, B., \& Van Knippenberg, A. (1998). Predicting behavior from actions in the past: repeated decision making or a matter of habit?. Journal of Applied Social Psychology, 28(15), 1355-1374. doi: 10.1111/j.15591816.1998.tb01681.x

American Educational Research Association, American Psychological Association, \& National Council on Measurement in Education - Aera. (2014). Standards for educational and psychological testing. Washington, DC: American Educational Research Association.

Ajzen, I. (2002a). Residual effects of past on later behavior: habituation and reasoned action perspectives. Personality and Social Psychology Review, 6(2), 107-122. doi: doi/ pdf/10.1207/S15327957PSPR0602_02

Ajzen, I. (2002b). Perceived behavioral control, self-efficacy, locus of control, and the theory of planned behavior. Journal of Applied Social Psychology, 32, 1-20.

Ajzen, I., \& Fishbein, M. (1980). Understanding attitudes and predicting social behavior. Englewood Cliffs, NJ: PrenticeHall.

Altman, B. M. (1981). Studies of attitudes toward the handicapped: The need for a new direction. Social Problems, 28(3), 321-334. doi: https://doi.org/10.2307/800306

Asch, S. (1971). Psicologia social. São Paulo: Cia. Ed. Nacional.

Bobbio, N. (2000). O futuro da democracia. São Paulo: Paz e Terra.

Bobbio, N., Matteucci, N., \& Pasquino, G. (1986). Dicionário de politica (C. C. Varrialle, G. Lo Mônaco, J. Ferreira, L. G. P. Cacais e R. Dini, trads.). Brasília: Editora da Universidade de Brasília.

Camino, L. (1996). Uma abordagem psicossociológica no estudo do comportamento político. Psicologia e Sociedade, $8(1), 16-42$.

Carneiro, T., Torres, C. V., \& Ekman, J. (2016). Political Participation in Brazil and Sweden: The Role of Stereotypes and Contagion. Psicologia: Teoria e Pesquisa, 32(spe), 1-10. https://dx.doi.org/10.1590/0102-3772e32ne223

Díaz, A. M. (2004). As atitudes políticas na Espanha, segundo uma estrutura dimensional indutiva. Opinião Pública, 10(1), 139-161. doi: http://dx.doi.org/10.1590/S010462762004000100006

Eagly, J., \& Chaiken, H. (1993). The psychology of attitudes. Fort Worth: Harcourt Brace.

Ekman, J., \& Amnå, E. (2012). Political participation and civic engagement: Towards a new typology. Human Affairs, 22(3), 283-300.

Fabrigar, L. R., Wegener, D. T., MacCallum, R. C., \& Strahan, E. J (1999). Evaluating the use of exploratory fator analy- sis in psychological research. Psychological Methods 4(3), 272-299.

Farr, R. M. (2001). As raizes da psicologia social moderna. Petrópolis: Vozes.

Fazio, R. H., \& Olson, M. A. (2003). Implicit measures in social cognition research: Their meaning and uses. Annual Review of Psychology, 54, 297-327. doi: 10.1146/annurev. psych.54.101601.145225

Fehr, E., \& Fischbacher, U. (2004). Social norms and human cooperation. Trends in cognitive sciences, 8(4), 185-190.

Fishbein, M., \& Azjen, I. (1975). Belief, attitude, intentions and behavior: an introduction to theory and research. Boston: Addison-Wesley.

Friedman, J. L., Carlsmith, J. M., \& Sears, D. O. (1970). Psicologia Social. São Paulo: Cultrix.

Gagné, R. M., \& Medsker, K. L. (1996). The conditions of learning: training applications ( $4^{\mathrm{a}}$ ed.). Belmont: Wadsworth Group/Thompson Learning.

Glasman, L. R., \& Albarracín, D. (2006). Forming attitudes that predict future behaviors: a meta-analysis of the attitudebehavior relation. Psychological Bulletin, 132(5), 778-822. doi: 10.1037/0033-2909.132.5.778

Gomes, M. D. A., \& Maheirie, K. (2011). Passe Livre Já: participação política e constituição do sujeito. Revista Psicologia Política, 11(22), 359-375.

Hair, J. F., Black, W. C., Babin, B. J., \& Anderson, R. E. (2010). Multivariate Data Analysis. Porto Alegre: Bookman.

Kraus, S. J. (1995). Attitudes and the prediction of behavior: A meta-analysis of the empirical literature. Personality and Social Psychology Bulletin, 21(1), 58-75.

Miller, A., Hesli, V., \& Reisinger, W. (1995). Comparing citizen and elite belief systems in post-Soviet Russia and Ukraine. Public Opinion Quarterly, 59(1), 1-40.

Myers, D. G. (1999). Social psychology. Nova York: McGrawHill College.

Nascimento, T. G., Torres, C. V., \& Pimentel, C. E. (2011). Evidências de validade e precisão da escala de atitudes frente à polícia. Revista Brasileira de Segurança Pública, 5(9), 42-56.

Oskamp, S., \& Schultz, P. W. (2005). Attitudes and opinions. Mahwah, NJ: Lawrence Erlbaum Associates.

Pasquali, L. (1999). Testes referentes a construto: Teoria e modelo de construção. Em L. Pasquali (Org.), Instrumentos psicológicos: Manual prático de elaboração (pp. 37-71). Brasília: Labpam.

Pereira, C., Lima, M. E., \& Camino, L. (2001). Sistemas de Valores e Atitudes Democráticas de Estudantes Universitá- 
rios de João Pessoa. Psicologia: Reflexão e Crítica, 14(1), $77-190$.

Pereira, C., Torres, A. R. R., \& Barros, T. S. (2004). Sistemas de Valores e Atitudes Democráticas de Estudantes Universitários. Psicologia: Teoria e Pesquisa, 20(1), 1-10.

Prothro, J., \& Grigg, C. (1960). Fundamental principles of democracy: Bases of agreement and disagreement. Journal of Politics, 22(2), 276-294. Recuperado de http://www.uvm. edu/ dguber/POLS234/articles/prothro.pdf

Reisinger, W., Miller, A., Hesli, V., \& Maher, K. (1994). Political values and Russia, Ukraine and Lithuania: Sources and implications of democracy. British Journal of Political Science, 24(2), 183-223. doi: 10.1017/S0007123400009789
Rodrigues, A., Assmar, E. M. L., \& Jablonski, B. (2012). Psicologia social. Rio de Janeiro: Editora Vozes.Rousseau, J. J. (1978). Discurso sobre a origem e os fundamentos da desigualdade entre os homens (L. S. Machado, trad.). ( $2^{\mathrm{a}}$ ed.). São Paulo: Abril Cultural.

Tabachnick, B. G., \& Fidell, L. S. (2001). Using Multivariate Statistics ( $4^{\mathrm{a}}$ ed.). Nova York: HarperCollins.

Tamayo, A., Pimenta, M., Rolim, M., Rodovalho, O., \& Castro, P. (1996). Prioridades axiológicas e orientação política. Psicologia: Teoria e Pesquisa, 12(3), 253-259.

Wallace, D. S., Paulson, R. M., Lord, C. G., \& Bond, C. F., Jr. (2005). Which behaviors do attitudes predict? Metaanalyzing the effects of social pressure and perceived difficulty. Review of General Psychology, 9(3), 214-227. 